\title{
Corrigendum to "Milk urea nitrogen variation explained by differences in urea transport into the gastrointestinal tract in lactating dairy cows" (J. Dairy Sci. 104:6715-6726)
}

\section{C. Souza, M. Aguilar, M. Van Amburgh, W. A. D. Nayananjalie, and M. D. Hanigan}

On pages 6721 and 6723 , Figures 2 and 3 were incorrectly matched with their captions. The corrected figures are shown below.

On page 6721, the second and third sentences should read (corrected text in bold), "Although flux into the GIT was not correlated with MUN $(P=0.88)$, the GIT clearance rate was highly correlated (Figure 3a; $P=$ $0.02)$, as were UUE $(P=0.05)$ and UUA $(P=0.03)$. The relationship with UUE appears to be a mass-action relationship, as MUN was not related to kidney transport activity (data not shown; $P=0.33$ ). In addition, kidney clearance rate was only weakly related to PUN $(P=0.13)$ in simple regressions.

On page 6723, the first two sentences should read, "The fractional transfer of UER to the GIT (GER/UER), which averaged $70 \%$, tended to be negatively related to MUN $(P=0.06$; Figure $3 \mathrm{~b})$, and PUN $(P=0.003$; Figure $2 \mathrm{~b})$. The GIT urea clearance rates were negatively correlated with PUN and the latter positively related with MUN $(P=0.02$; Figure 2a).

\section{REFERENCES}

Souza, V. C., M. Aguilar, M. Van Amburgh, W. A. D. Nayananjalie, and M. D. Hanigan. 2021. Milk urea nitrogen variation explained by differences in urea transport into the gastrointestinal tract in lactating dairy cows. J. Dairy Sci. 104(6):6715-6726. https://doi.org/10.3168/ jds.2020-19787.

$\mathbf{A}$

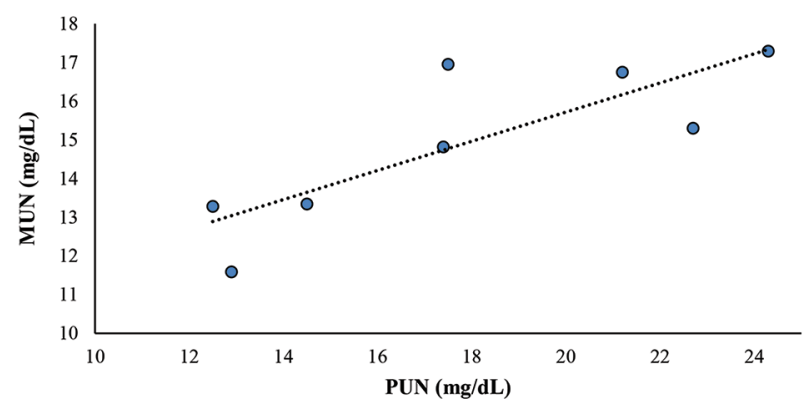

B

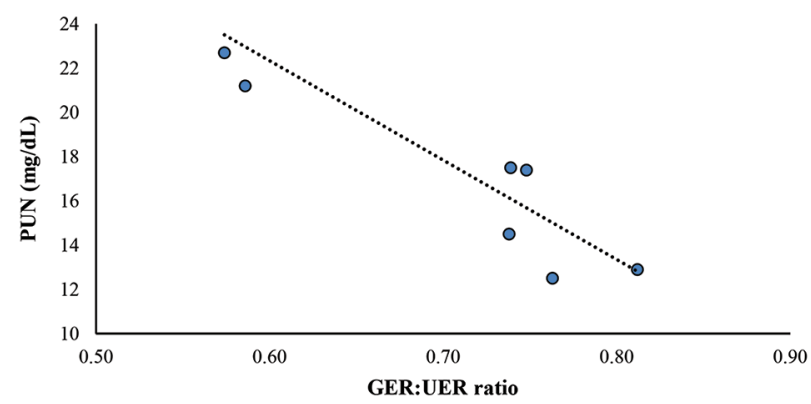

Figure 2. (A) Plasma urea nitrogen (PUN) versus observed MUN. MUN $(\mathrm{mg} / \mathrm{dL})=0.38(\mathrm{PUN} ; \mathrm{mg} / \mathrm{dL})+8.18 ; \mathrm{R}^{2}=0.68 ; P=0.01$ (B) Gastrointestinal entry rate relative to urea $\mathrm{N}$ entry rate to gastrointestinal tract (GER:UER ratio) versus PUN during the $3 \mathrm{~d}$ infusion of $\left[{ }^{15} \mathrm{~N}^{15} \mathrm{~N}\right]$ urea. PUN $(\mathrm{mg} / \mathrm{dL})=-44.3$ (GER:UER ratio) $+49.3 ; \mathrm{R}^{2}$ $=0.79 ; P=0.003$.
$\mathbf{A}$

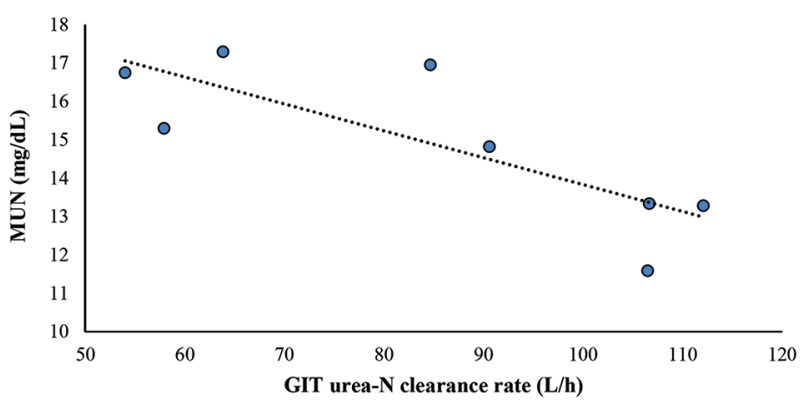

B

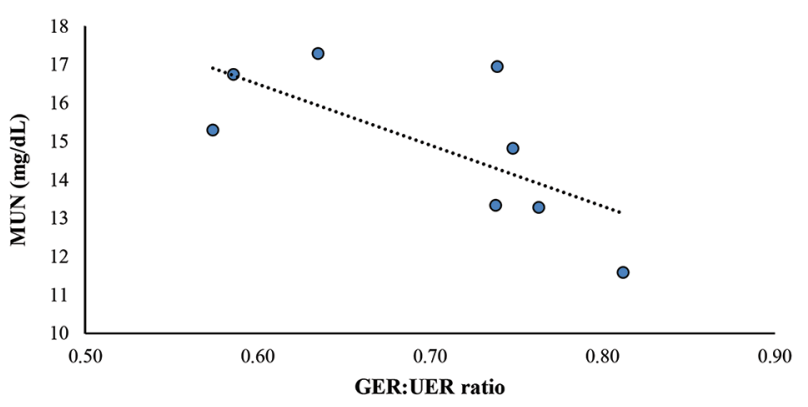

Figure 3. (A) Gastrointestinal tract (GIT) urea clearance rates versus observed MUN during the 3 -d infusion of $\left[{ }^{15} \mathrm{~N}^{15} \mathrm{~N}\right]$ urea. MUN $(\mathrm{mg} / \mathrm{dL})=-0.07($ GIT urea clearance rate $\mathrm{L} / \mathrm{h})+20.8, \mathrm{R}^{2}=0.64$, $P=0.02$. (B) Gastrointestinal entry rate relative to urea $\mathrm{N}$ entry rate (GER:UER ratio) versus observed MUN during the $3 \mathrm{~d}$ infusion of $\left[{ }^{15} \mathrm{~N}^{15} \mathrm{~N}\right]$ urea. MUN $(\mathrm{mg} / \mathrm{dL})=-15.9$ (GER:UER ratio $)+26.0 ; \mathrm{R}^{2}=$ $0.47 ; P=0.06$. 